Revista Iberoamericana, Vol. LXXVI, Núm. 232-233, Julio-Diciembre 2010, 695-712

\title{
LA INVENCIÓN DE LA HISTORIA: ABILIO ESTÉVES Y LAS RUINAS DE UN TEATRO
}

\author{
POR \\ IvetTe GóMEZ \\ University of California-Irvine
}

I do love these ancient ruins:

We never tread upon them, but we set

our foot upon some reverend history.

John Webster, The Duchess of Malfi Act V, Scene III

Aquí está todo, repite el payaso, la Isla entera puede hundirse mañana mismo, lo que no puede desaparecer son las ruinas de este teatro.

Abilio Estévez, Los palacios distantes 264

En la literatura cubana de finales del siglo xx y principios del xxI, el tema de las ruinas abunda. La marcada presencia de este tópico, para nada exclusivo a la literatura del período, no resulta extraña si la mirada del lector se mueve de la escritura a la ciudad, del texto a La Habana del llamado "Periodo Especial”. Este período de nomenclatura eufemística, que suele clasificar la etapa de crisis económica que sobreviene en la isla a raíz de la caída del campo socialista de la Europa del Este, no hace sino acentuar la decadencia en que ya se sumergía la ciudad luego de casi cuatro décadas de Revolución. ${ }^{1}$ Las constantes alusiones, en la literatura cubana de este período, a una Habana delimitada por "zonas de derrumbes", sostenida por apuntalamientos, inundada de basura, desnuda de colores y con piedras "al desnudo", no hacen sino referir una realidad. Las ruinas son, con razón, el símbolo más emblemático de la capital (y por tanto de la nación) cubana finisecular; de ahí la abundante producción literaria que se reúne alrededor del tema.

La recurrencia del tópico de las ruinas en la literatura cubana de fin de siglo xx y principios del xxı no deja de contener la expresión de la desilusión, del desencanto

1 En Invención de La Habana la arquitecta Emma Alvarez-Tabio Albo sugiere que el deterioro de la ciudad es en gran parte resultado de un abandono consciente por parte del Estado cubano: "En realidad la revolución de enero de 1959 vuelve la espalda a la capital, oportunamente identificada con la corrupción de los gobiernos republicanos y con los vicios del american way of life” (371). 
que la crisis del "Periodo Especial" provoca en la sociedad cubana. Como nota Peter Fritzsche en su libro Stranded in the Present, entre todas las posibilidades de acercamiento a las ruinas que existen -la estética (el verlas como pura obra de arte), la naturalista (el considerarlas como marcadores de una capitulación y reintegración del arte a la naturaleza), o la filosófica (el alegorizarlas como signo de la descomposición de todas las cosas)-, existe también la posibilidad histórica: el percibirlas como "representaciones de una tragedia nacional” (94), como metáforas de una crisis nacional plantada (stranded) en el presente. ${ }^{2}$ Según Fritzsche el acercamiento a las ruinas se produce así con la esperanza de encontrar alivio para la tragedia, una alternativa para el presente, ya que "dado su potencial evocativo, la ruina es atesorada por su habilidad de referir un esquema histórico alternativo" (105, mi traducción). Este potencial evocativo que enfatiza el crítico en las ruinas está dado por su capacidad de poseer, como fragmentos del pasado, una presencia viva, a "half-life", que tiene el poder tanto de inspirar como de atemorizar. En su libro, Fritzsche reconoce, al fin, la capacidad que tienen las ruinas de crear una relación dinámica y epistemológica con el pasado.

En la literatura cubana, y principalmente en la narrativa cubana de estos últimos quince años, el extenso corpus temático de las ruinas ha producido también textos que, escapando a la exclusiva referencialidad inmediata que suele producir el tropo, se involucran, participan de esta dinámica con el pasado que refiere Fritzsche en su texto. No son muchos los ejemplos que se resisten a la tentación de presentar las ruinas de La Habana como meros referentes de la debacle, sin ahondar mucho en la posibilidad cognitiva, crítica y creativa, que estas suscitan, pero, afortunadamente, se pueden mencionar algunos. Este trabajo propone el análisis de uno de estos últimos casos: el del narrador, poeta y dramaturgo Abilio Estévez (1954), en quien las ruinas habaneras de fin de siglo xx y principios del xxı encuentran una de sus más sofisticadas representaciones, estilísticamente hablando.

Quizás una de las variantes más nostálgicas de aproximación a las ruinas que se dan dentro de la narrativa cubana de estos últimos quince años, la presencia del tema en la escritura de Estévez no deja de generar un marco para la reflexión crítica. Es precisamente la ambivalencia que el tropo "ruina" adquiere en este autor, lo que lo hace particularmente interesante para este estudio. En Estévez, las ruinas actúan como vehículos expresivos de varias paradojas: éstas proveen la posibilidad de mostrar tanto una circunstancia de pérdida como una de recuperación; anuncian tanto una ausencia

2 En su libro Fritzche estudia el imaginario de las ruinas en relación a la Revolución francesa, específicamente a los estragos causados por la invasión napoleónica en Alemania, los que hacen que Dorotea Schegel se refugie en las ruinas del valle del Rin "para rescatar la memoria de la nación de su eterno presente imperial” (95, mi traducción). Según el crítico, Schegel creía que el juego azaroso de la política revolucionaria había hecho un corte radical de su vínculo con el pasado y la había condenado a permanecer "plantada” en el presente (93).

ISSN 0034-9631 (Impreso) 
como una presencia. Si las ruinas, en la escritura de este autor habanero, dan testimonio de la crisis económica y moral que sufre la sociedad cubana a finales de los noventa, si dan cuenta del “desencanto” asociado a la pérdida de la ilusión en la edificante utopía socialista invocada por el gobierno cubano durante cuatro décadas, éstas también revelan la expresión de un "encanto”. Este encanto puede ser entendido en la connotación que tiene el sustantivo de “atracción” y de “conjuro”, pues el tópico de las ruinas - a juzgar por la manera en que se repite y cobra importancia en la obra de Estévez- contiene una carga considerable de seducción y favorece la invocación de ciertos espectros o fantasmas del pasado. ${ }^{3}$

Las ruinas, como indica Andreas Huyssen en un ensayo dedicado al análisis de la nostalgia que convocan las mismas, contienen la presencia de ciertos "fantasmas" que es posible sacar a luz. Es en esta presencia espectral donde Huyssen ubica el aura de "lo uncanny", el elemento misterioso, peligroso que suelen contener las ruinas. Una de las principales manifestaciones de "lo uncanny" es la simultaneidad de tiempos y espacios que hay presente en ellas: una característica que, según el comparatista y estudioso de literatura alemana, es lo que produce el ambiguo resultado de atentar y añorar la Modernidad. ${ }^{4}$ La nostalgia en el análisis de Huyssen adquiere, así, cierta connotación positiva, pues no impide la oposición entre lo crítico y lo melancólico.

El objetivo de este trabajo es analizar, precisamente, el contenido melancólico, nostálgico, de la escritura de Estévez. Partiendo de la concepción freudiana que explica la melancolía como un proceso en el que la confrontación con la pérdida no parece resolverse (diferente al proceso de duelo -“mourning”- en el que la pérdida se asimila mejor), este estudio se propone examinar los modos en que Estévez enfrenta lo perdido tanto en el presente como en el pasado. ${ }^{5}$ Se trata, en otras palabras, del análisis del posicionamiento que asume la escritura de este autor con respecto a la historia, la inmediata y la anterior

3 El tópico de las ruinas cobra protagonismo en varias obras de Estévez. Aparte de la novela que se analizará en este ensayo, Los palacios distantes (2002), las ruinas de La Habana están también presentes en la primera novela del autor, Tuyo es el reino (1997) y en el cuento “Tosca” en el volumen El horizonte y otros regresos (1998). La Habana en ruinas es, de igual manera, la protagonista de las memorias autobiográficas de Estévez, Inventario secreto de La Habana (2004), que son también las memorias de la ciudad.

4 En el ensayo "Nostalgia for Ruins”, Huyssen analiza la producción de "fantasmas” que las ruinas tienden a "resucitar" (16). Utilizando como modelo de análisis el cuadro "Carceri d’invenzione” del pintor italiano del siglo XVIII, Giovanni Battista Piranessi, el crítico argumenta que las ruinas invocan un "aura” aterradora, que se justifica en la simultaneidad de tiempos y perspectivas que éstas contienen. En este ensayo Huyssen recuerda también que la yuxtaposición no-lineal de múltiples temporalidades presente en las ruinas, actúa como un contra-discurso de la narrativa racionalista y progresiva, prometedora de futuros mejores de la Modernidad occidental. Al mismo tiempo, el acercamiento a las ruinas, puede encubrir una nostalgia por una etapa temprana de la modernidad, cuando todavía no se había desvanecido la posibilidad de imaginar "futuros mejores” (21, la traducción es mía).

5 Sigmund Freud."Mourning and Melancholia”.

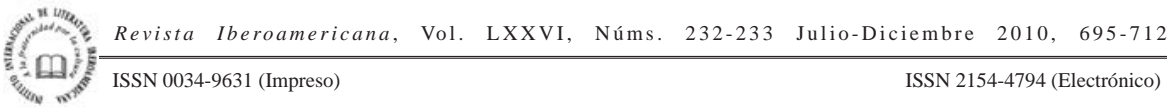


a su escritura. Si, como ya se mencionó, el encanto por las ruinas supone el conjuro de ciertos "fantasmas", en este trabajo se tratará de determinar los espectros o fragmentos del pasado que la escritura de Estévez invoca. De este modo se pretende investigar la relación que entabla este autor no sólo con la historiografía oficial, sino también con la tradición literaria que le antecede, especialmente con una narrativa donde las ruinas incitan un uso de la memoria en una escritura que relaciona el espacio urbano y el de lo nacional en la elaboración de propuestas identitarias y culturales de "lo cubano". Se considerará así, en este ensayo, las continuidades y rupturas que se dan entre Estévez y otros narradores del canon de las letras cubanas como Alejo Carpentier, José Lezama Lima, Virgilio Piñera, entre otros. El texto principal que guiará este análisis es Los palacios distantes (2002), la segunda novela de este escritor en la que, a La Habana de finales de siglo xx y principios del xxı, sirven de arquetipo las ruinas de un teatro.

\title{
RELATO DE UN (DES)ENCANTO
}

Los palacios distantes abre con una imagen de ruinas contenedora de un profundo sentido de devastación, duda y desolación:

\begin{abstract}
El antiguo hotel Royal Palm en la calle Galiano y el viejo palacio de una familia de abolengo cuyo apellido ya nadie recuerda son construcciones unidas por el mutuo destino de los puntales. Entre un edificio y otro han colocado una enmarañada trama de vigas y horcones que intenta afincarse en cuanto parezca exhibir alguna esperanza de solidez. Ennegrecidas por el paso de tantos días y noches, por la dureza del sol y las turbonadas, por la ubicuidad de las sales marinas, las tablas pretenden impedir un derrumbe que de cualquier modo parece inminente. Las paredes muestran el color terroso, gris y negro de los muros viejos en cualquier ciudad devastada en un mundo donde abundan guerras, terremotos y otras catástrofes menos evidentes. Las piedras están desnudas en muchos sitios, con tonos sorprendentes y rojizos, y grietas en los muros que sin embargo permiten crecer helechos opulentos, verdes inesperados entre el derrumbe. (17)
\end{abstract}

Una imagen decadente que sin lugar a dudas expresa un desencanto, metaforizado por el desgaste, el apuntalamiento y la inminencia de la desaparición, no deja, sin embargo, de transmitir cierto encanto. Este encanto se alegoriza también en este pasaje en la presencia del "verde" que surge "inesperadamente" de la piedra desnuda. Convocador de cierta esperanza, este verde entre las grietas será la primera manifestación de que el texto de Estévez - diferente a tantos otros relatos que insisten en abordar sólo el lado "sucio" y oscuro de la decadencia habanera finisecular- habrá de explorar la otra cara de las ruinas. La certeza de esta posibilidad se ratifica en comprender que, a raíz de la piadosa demolición que impide el inminente derrumbe de uno de estos edificios -el

Revista Iberoamericana, Vol. LXXVI, Núms. 232-233 Julio-Diciembre 2010, 695-712
ISSN 2154-4794 (Electrónico) 
otrora palacio, ahora solar-, empiezan las (des)aventuras de Victorio por La Habana y, con ellas, el inicio de la historia de la novela.

El personaje principal de Los palacios, Victorio -el cuarentón al que el derrumbe del "palacio" deja sin hogar- puede ser considerado un prototipo del desencanto, de la pérdida, de la desilusión. Debiendo su nombre al fanatismo revolucionario de su padre, quien a su vez recibe la alegórica e irónica nomenclatura de “Papá Roberspierre”, este personaje fue nombrado a raíz de una fecha histórica: la del asalto de Fidel Castro y otros revolucionarios al Cuartel Moncada de Santiago de Cuba el 26 de julio de 1953. A parte de nunca compartir el entusiasmo por la Revolución que profesaba el padre-quien en enero de 1959 le llevara a presenciar la entrada de los rebeldes a La Habana, un episodio que definía como el "inicio de la Historia”-, Victorio tampoco pudo llegar a las expectativas del “Hombre Nuevo” enarboladas por él: su homosexualismo no lo permitió. Mientras más se esforzaba "Papá Robespierre" en fortalecer el coraje de su "macho, nacido con ocho libras el día de un acto heroico", vistiéndolo con trajes de miliciano que “cubrían de sarpullido su tierna piel” y dejándolo solo por diez minutos en la oscuridad de la casa (método pedagógico sacado de un texto de Antón Makarenko), menos se daba cuenta del ser aterrorizado, taciturno y melancólico que formaba. Mientras más idealista el padre frente a la Revolución y la Historia, más vencido el hijo frente a éstas.

El sentir de la derrota, de la desilusión que se mantiene en Victorio adulto se transforma en posibilidad restauradora, renovadora en el momento que el personaje decide asumir su nueva condición de vagabundo. La falta de ataduras al espacio de su cuartucho de solar y al tiempo laboral -en una escena el personaje se deshace de su reloj para luego exclamar: "Si no hay reloj [...] no hay tiempo, y, si no hay tiempo, he llegado a la eternidad [...] Se acabó el tiempo, soy inmortal” (60)- le ofrece a Victorio la posibilidad de experimentar una libertad anteriormente desconocida: la de convertirse en un verdadero “nómada posmoderno”, en un verdadero “ciudadano”, esto es, habitante de la ciudad. ${ }^{6}$ En su nueva condición de vagabundo Victorio recorre La Habana del nuevo milenio y la descubre en toda su decadencia y esplendor. A través de estos recorridos el sensible cuarentón reconoce, escruta y descifra los signos de una ciudad paradójica y ambivalente, una ciudad que "provoca a un tiempo dos impresiones, la de haber sido bombardeada, la de una ciudad que espera el más leve aguacero, la más ligera ráfaga para deshacerse en montón de piedras; y la de ser una ciudad suntuosa y eterna, acabada de construir, elevada como cesión a futuras inmortalidades” (21). En

6 Utilizo aquí un concepto del sociólogo Zygmunt Bauman, quien en Ética posmoderna, describe al "vagabundo" como una metáfora más acertada que el "nómada" para describir el constante movimiento, la falta de destino y de sentido del tiempo, todos éstos, predicamentos del "hombre y la mujer posmoderna". Según Bauman, lo que mantiene al vagabundo en movimiento es "la desilusión con el lugar donde acaba de estar y la siempre latente esperanza de que el siguiente lugar, que aún no ha visitado, o quizás el que siga después de ese, esté libre de los defectos que le repulsaron en los lugares que probó” (273).

ISSN 0034-9631 (Impreso) 
esta ciudad contradictoria, el personaje lo mismo encuentra violencia que solidaridad, una mano que le golpea y le roba como otra que le ayuda y le da de comer. Son éstas dos caras de La Habana (y de la crisis), las que Estévez resalta con insistencia en su novela, la cual, marcada por el tropo de las ruinas, enfatiza la contradicción y la ambigüedad.

La Habana de Los palacios se describe como "la ciudad de las columnas" (y en este sentido no deja de recordar a ratos a aquella descrita por Carpentier, como tampoco Victorio deja de aludir al "José Cemí” lezamiano y a sus agudas y memoriosas reflexiones sobre la ciudad) y la "ciudad de los derrumbes". ${ }^{7}$ Es una ciudad llena de ruinas en las que Victorio no sólo encuentra refugio, sino también amistad. En las ruinas de un asilo para impedidos mentales el vagabundo halla precisamente eso, "asilo" por unas cuantas noches y, en las ruinas de la antigua muralla que protegía a la ciudad colonial, Victorio conoce a Salma, una joven que se ha de convertir en su compañera de andanzas y aventuras citadinas y en otro de los personajes principales de la novela. Compartiendo la suerte del cuarentón, esta joven también puede considerarse otra encarnación del desencanto. Salma, cuyo nombre verdadero es Isabel, es una "jinetera" o prostituta que sueña con escaparse de La Habana y vivir la vida de una estrella de Hollywood; de ahí que prefiera llamarse como la actriz mexicana (Salma Hayek). Históricamente desmemoriada -al aclararle Victorio que debe su nombre al asalto al cuartel Moncada, Salma replica despistada: "Yo no sé nada de ese cuartel, tú, no tengo memoria" (55)-, fanática de la cultura popular americana y de la cubana alternativa, Salma representa a la nueva generación de cubanos, a ese "hombre nuevo" malogrado que Victorio ya venía anunciando.

Estos dos personajes cuya diferencia de edad, gustos y nivel cultural apartan, encuentran un punto en común en su deseo de escape de una realidad alienante y desoladora. Este escape que no llega a producirse por vía de lo marítimo o lo aéreo (la novela presenta recurrentes motivos como avionetas, globos y el primer "balsero" cubano Matías Pérez), se produce por medio de lo artístico, pues el último y más importante refugio que Victorio encuentra, esta vez junto a Salma, son las ruinas de un teatro: el "Pequeño Liceo de La Habana”, cuyas puertas les abre Don Fuco, el tercer personaje principal de la novela. Un viejo payaso capaz de realizar actos sorprendentes como hacer, vestido de Pierrot, contorsiones y equilibrios en las maderas de los apuntalados y derruidos edificios habaneros, Don Fuco da cuerpo al espíritu de magia y fantasía que

7 En la novela de Estévez es incluso posible reconocer descripciones de la ciudad que continúan la visión carpenteriana del característico "tercer estilo" habanero: "un ecléctico edificio [...] blanco-gris-azulamarillento, adornado, atiborrado de peligrosos balcones y ventanas infructuosas. Sucio. Adornado. Habanero. Sumamente habanero el edificio sucio y adornado. Aire París-Barcelona-Cádiz, o sea, habanero. Altas columnas y soportales para defender al infeliz transeúnte de las asperezas y desmesuras de soles y lluvias y calinas desalmadas. La fachada ostenta varias puertas y algunas, la mayoría no son originales. ¿Qué es original y qué no en esta ciudad?” (251).

ISSN 0034-9631 (Impreso) 
tanto Salma como Victorio encuentra en las ruinas del teatro. Dedicado a regalar un poco de entretenimiento y alegría a los taciturnos y alicaídos transeúntes de La Habana del "Periodo Especial”, el viejo payaso también declara un profundo desencanto con la realidad: "me ha tocado sobrevivir al fracaso de las grandes empresas de los hombres, y no hay más, lo advierto, nada más que esto, la decepción” (101). La decepción de Don Fuco dista de ser circunstancial; ésta es más bien histórica, pues, similar al Ti Noel carpentariano de El reino de este mundo, el personaje representa a la Historia, o mejor, a su Testigo, el testigo de las grandezas y catástrofes de la historia política cubana: una experiencia que el texto opone a la experiencia de lo cultural, del arte cubano y universal.

La ambigüedad de la experiencia histórica de Don Fuco corresponde a las ruinas del teatro que habita. Éste, como la ciudad que lo sostiene, está marcado por la combinación de esplendor y decadencia. A pesar de ser un teatro destrozado que yace olvidado en la memoria habanera, el Pequeño Liceo mantiene todavía signos de su antiguo encanto, restos de una “gloriosa y lejana época”:

Columnas toscanas, dóricas, corintias, jónicas. Columnas de órdenes compuestos. Cariátides sonrientes y tristes (la comedia, la tragedia). [...] Restos de palcos con amanerados barandales de hierro y pasamanería de madera con adornos griegos, romanos, bizantinos. [...] Las lámparas, los restos de las lámparas, van desde la gran araña hasta las de una sola luz, escuetas lámparas con bombillas azules. [...] Entre el destrozo del patio de butacas, pueden verse algunas en buen estado. [...] Sobrio, escueto, a la italiana, el escenario puede ser mucho mayor de lo que a simple vista parece; se diría que han sido las tablas de la escena la que con mayor coraje han logrado soportar calamidades del clima, los años y de tantas larvas. [...] Al fondo del escenario se hallan los cuatro camerinos, con las estrellas de metal pegadas a las puertas, capaces aún de revelar el centelleo de lentejuelas y abalorios. (93-94)

Una descripción, cargada de barrocas pinceladas al estilo carpentariano y lezamiano, que relata el encuentro de Victorio con las ruinas del teatro, insiste en referir lo que sobrevive en medio del desastre. Y es que, como Don Fuco, el Pequeño Liceo ha sobrevivido a las catástrofes de la Historia y conserva entre sus derruidas paredes una magia imperecedera. Más que a lo desaparecido, las ruinas de este teatro apuntan a lo que permanece; de ahí que la permanencia de Victorio y Salma en el Pequeño Liceo, sea lo que determine la anagnórisis de estos personajes: el reconocimiento mutuo y el conocimiento de un gusto por lo estético y por una ética que perdura aún en medio de la mediocridad, el mal gusto y la debacle de los valores morales en La Habana del "Periodo Especial".

\footnotetext{
Revista Iberoamericana, Vol. LXXVI, Núms. 232-233 Julio-Diciembre 2010, 695-712 ISSN 0034-9631 (Impreso) 
EN EL PRINCIPIO FUE EL TEATRO

En Los palacios distantes, las ruinas del teatro, más que un final (el último refugio), representan un principio. Ellas dan pie al “Génesis” de la novela, su verdadero comienzo, precisado por el inicio del aprendizaje de Salma y Victorio, versión singular de la primera pareja: de Adán y Eva. En las ruinas del “Pequeño Liceo de La Habana” estos personajes no sólo aprenden sobre sí mismos, sus historias personales (los temores de la infancia y las soledades de la adultez, los amores perdidos y no correspondidos, las confesiones de cómo Victorio se hizo homosexual y Salma jinetera), sino también aprenden una historia que no consta en los anaqueles oficiales de la nación: la historia particular, oculta y secreta del teatro. Por boca de Don Fuco, Salma y Victorio se enteran que el "Pequeño Liceo" fue construido por orden de una joven, culta, bella y adinerada princesa rusa, Marina Voljovskoi, quien huyendo de Europa a causa de sus contrariados amores con el negro violinista cubano Claudio Brindis de Salas, llega a La Habana, para asentarse en ella, a principios del siglo xx.

Detrás de una modesta fachada, un oscuro pasillo y una oculta escalera, la princesa Voljovskoi construyó su templo a la belleza y la gloria del arte, pues en su pequeño e ignorado teatro bailaron Ana Pavlova y Nijinsky, cantaron Enrico Caruso y María Callas y desfilaron Pau Casals, Ella Fitzgerald, Antonín Artaud, Jean Marais (con Jean Cocteau), María Félix (con Jorge Negrete), Michèle Morgan y Galina Ulánova, Celina González y Cora Vaucaire, Alicia Alonso y Miko Yana; todos frente a los asombrados y admirados ojos de la princesa y su mejor amigo, Don Fuco: los únicos espectadores. Las ruinas del “Pequeño Liceo” retienen, según Don Fuco, el “espíritu” de estos artistas, guardan el espectro de un valioso capital cultural en el que "lo universal" se funde con "lo cubano". Sitio de "lo nacional/universal", las ruinas del teatro guardan no sólo recuerdos, pero también reliquias, las "reliquias de la patria”, un tesoro conformado por:

[L]os vestidos de Rita Montaner, de Barbarito Diez, de Beny Moré, de Celia Cruz, de Alicia Alonso, [...] los manuscritos de tantos escritores famosos, las guitarras de María Teresa Vera, de Manuel Corona, de Pablo Milanés y Marta Valdés, el piano de Lecuona, objetos de Alicia Rico, Candita Quintana, Esther Borja, Miriam Acevedo, Iris Burguet y Blanquita Becerra, la camisa ensangrentada de Julio Antonio Mella, el mantel también ensangrentado de los Lamadrid en cuya mesa murió Julián del Casal, lienzos de Portocarrero, de Amelia, de Tomás Sánchez, de Acosta León, de Raúl Martínez, piezas de Ñica Eiriz. (134-135)

Además de todas estas reliquias que Don Fuco enumera para Victorio, el viejo payaso considera faltan: "la voz de cristal de Pablo Quevedo, [...] el sabor del níspero, el olor de la lluvia, el rocío del valle de Viñales, [...] el llanto de algunos de los que se echaron al mar de 1994, en aquellas balsas precarias, [...] muestras de las trágicas

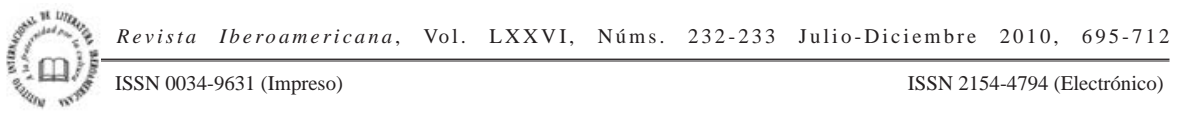


despedidas en los aeropuertos, el resonar de los cascos de los caballos en la batalla de Mal Tiempo"(135). Todos estos son, como diría Walter Benjamin, objetos que hablan, que apuntan a una historia que debe ser recuperada; y es la recuperación de esta historia, de esta memoria particular la que marca el texto de Estévez. ${ }^{8}$

Las ruinas del teatro permiten la evocación de una memoria integradora. Las "reliquias de la patria" son objetos que alegorizan no sólo la fusión del arte nacional y del universal (donde se incluye, incluso, elementos de una cultura que en el "Período Especial” cubano tiende a la desaparición: la rusa), también ellas rememoran glorias y catástrofes de la historia política y cultural cubana. La historia contenida en estos fragmentos se proponen así como la posibilidad "otra" de la "Historia Oficial". Las "reliquias de la patria" no apuntan únicamente al relato de "lo heroico" que suelen llenar los anaqueles históricos oficiales: no son "reliquias que llaman sagradas, sino las otras, las verdaderas, las reliquias profanas, esas que no son épicas, las que no sirven como arma de guerra" (135). Estos objetos se contraponen al discurso mítico que maneja la Historia y muestran lo que suele de haber en ella de inventivo, de artificioso: un elemento esencial de las cosas que Salma y Victorio aprenden a reconocer en el teatro.

En las ruinas del "Pequeño Liceo” Victorio y Salma se ponen en contacto directo con el mundo del artificio. En este sitio, por excelencia, de "lo performativo", los personajes aprenden sobre el arte del maquillaje, del enmascaramiento, del disfraz, del travestismo. Iniciados en este arte por Don Fuco, Salma y Victorio sufren una transformación, un nuevo descubrimiento de sí mismos a partir de la posibilidad de convertirse en otros: exploran sus capacidades imaginativas. Es así como ambos se entrenan en el arte de la transfiguración, de la actuación. Bajo la tutela de Don Fuco, Salma y Victorio desarrollan la magia, la mímica, la declamación y la contorsión; aprenden sobre la tragedia y la comedia y la tenue línea que separa a la primera de la segunda: pues basta que "se encuentren dos gravedades unidas" para "crear una fuerza de signo contrario" y hacer reír (196). Esta teoría de la comicidad que puede producir el patetismo, la experimenta Victorio en carne propia, ya que luego de declamar en tono grave unos pesimistas alejandrinos de Rubén Darío y causar las carcajadas de Salma y Don Fuco, es considerado por éstos un verdadero "clown". ${ }^{9}$ Asumiendo su nuevo rol de "payaso", sale Victorio a las calles de La Habana vestido de Pierrot (exactamente al modo de Gilles del famoso cuadro de Watteau, con traje nácar de cuello redondo y mangas largas, con sombrero de alas anchas

8 La visión histórica del autor de Los palacios coincide así con la de Walter Benjamin, el que al considerar a la Historia como una serie de catástrofes, opta por alegorizarla bajo el signo de las ruinas. Para Benjamin las ruinas son anuncios de desastres y hecatombes pero son también depositarias de una esperanza. Ellas como la imagen del "Angel Novus", incitan un movimiento al futuro de cara al pasado ("Theses on the Philosophy of History” 257).

9 Este incidente asocia a Victorio con otro personaje de la narrativa cubana: "El gran Baro” payaso y personaje de un cuento homónimo de Virgilio Piñera, autor que tiene una presencia constante en la obra de Estévez y en especial en esta novela, como se verá más adelante.

ISSN 0034-9631 (Impreso) 
y zapatillas blancas adornadas con cintas rosadas y una lágrima roja dibujada en la cara) y, acompañando a Salma vestida de Marlene Dietrich en el “Ángel Azul”, participa de los estrafalarios espectáculos que monta Don Fuco con el propósito de entretener a los atribulados habitantes de La Habana del "Período Especial”:

Cierta noche que llevan su espectáculo al parque de los Filósofos, junto a una feria de carruseles y montañas rusas que han abierto a un lado del Anfiteatro de La Habana. Colocan entre los árboles los telones negros de una cámara oscura. Por luces, poseen sólo unos cuantos velones antiguos aferrados para siempre a enrevesadas palmatorias de bronce. Atraídos por lo extraño del tinglado, los paseantes comienzan a acercarse, hasta que se crea un nutrido grupo de curiosos frente a los feos telones. Se escucha la música de una flauta [...] Un Pierrot aparece entre los telones. Una lágrima de sangre fulgura en su mejilla. La actitud de Pierrot es de tristeza desánimo, desamparo [...] Levanta una mano y la música cesa al tiempo que se escucha una rara voz que dice: "No me mueve mi Dios para quererte/el cielo que me tienes prometido...” El público sufre la primera confusión. El público no sabe si deber reir. Hasta que felizmente alguien, el audaz de siempre, rompe el silencio con la primera carcajada. Envalentonado, el resto del público lo sigue. El poema finaliza entre un magnífico coro de risotadas. (206)

A través de estos espectáculos callejeros, el "performance" imaginativo trasciende el espacio de las ruinas del teatro para apropiarse de la ciudad. Se logra así que los actos transgresivos que ocurren en este espacio-la memorización alternativa, los travestismos identitarios- afecten también el espacio público y la memoria colectiva.

En la novela de Estévez, las ruinas del "Pequeño Liceo de La Habana” no dejan de funcionar como un arquetipo de la nación cubana. Estas ruinas no dejan de expresar también una sensación idílica, espiritual que se debe, en gran medida, a la contención que hay en ellas de un "espíritu” de cubanidad. En este sentido, las ruinas de Estévez parecerían establecer una conexión con aquellas invocadas en la escritura de Carpentier y Lezama, en quienes los espacios arruinados de la ciudad, especialmente de la ciudad colonial, son considerados depositarios de una esencia de "lo cubano.” Las ruinas del "Pequeño Liceo" no dejan de evocar esta "esencia”: ellas, al fin y al cabo, como ya se vio, contienen "las reliquias de la patria”. Sin embargo, en Estévez esencia no es sinónimo de "esencialismo", como suele ocurrir en las elaboraciones que sobre "lo cubano" hace la obra lezamiana y, en menor medida, la carpentariana. En el autor de Los palacios esta noción se conceptualiza, así, mucho menos fija y cerrada. Si en Carpentier y Lezama las ruinas coloniales dan acceso a una imagen precisa donde se deposita el "origen" de la cubanidad (el barroquísimo "carnaval de estilos", en el caso de Carpentier; la familia patricia y criolla, en el de Lezama), esta imagen está en constante cambio en el caso de Estévez. Esta propensión hacia la metamorfosis radica precisamente en el tipo de

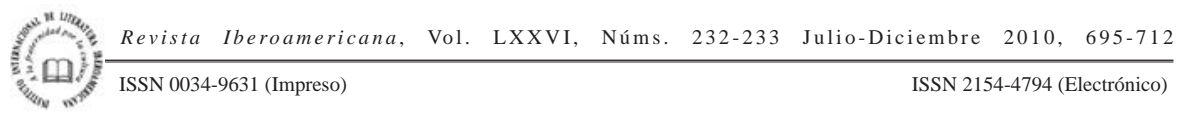


ruinas que escoge el autor en su novela: las ruinas de un teatro, en donde el elemento performativo permite la constante transformación de "lo identitario".

La máscara, el maquillaje y el disfraz que caracterizan al teatro propician no sólo la mutación, renovación e invención propia de los personajes (la posibilidad de cambiar de género, edad, nacionalidad y personalidad) mas también la del espacio físico en el que estos personajes habitan. La tramoya, los elementos escenográficos, los juegos de luces afectan de igual forma la constitución de este espacio. La presencia de estos elementos deja al descubierto el carácter artificial de cualquier situación que se desarrolle en el espacio del teatro y enfatiza la condición imaginaria de las propuestas que se elaboran en torno a él. La selección conciente del teatro como espacio alegórico de la nación en la novela, incluye la invitación a interpretar cualquier proposición sobre la misma desde el artificio, desde lo imaginativo. En este ejercicio concientemente inventivo, creativo, de “lo nacional”, interviene también el tropo ruinas, pues éstas, como el teatro, contienen también un elemento performativo que media con la imaginación del pasado a partir de los restos que quedan del mismo en el presente.

En el estudio interdisciplinario Theatre/Archaeology Mike Pearson y Michael Shanks reconocen tanto en el teatro como en la arqueología la presencia de un "performance" que interviene en la constitución inventiva de espacios físicos. Es este elemento performativo, presente en estos dos campos disímiles, el que hace posible visualizar la interacción no-linear entre presente y pasado. En el campo de la arqueología son las ruinas las que mejor representan esta dinámica, pero esto es sólo cuando las mismas no están restauradas. ${ }^{10}$ Como explican ambos especialistas, las ruinas históricas abiertas al público son conservadas de manera que producen la experiencia de un "simulacro" de ruina (una copia de un original que nunca existió). En la arqueología tal "limpiamiento" oscurece los "fantasmas" que esos sitios generan, minimizando la riqueza interpretativa de tales lugares (92). Contrario al estudio de este tipo de ruinas, la investigación arqueológica en ruinas sin restaurar produce la posibilidad de descubrir un "mapa profundo" de complejas narrativas "en competencia" que se abre a la posibilidad de interpretación crítica (158-159). Estos sitios arqueológicos no restaurados, en los que es posible "leer entre líneas" muestran, según Pearson and Shanks: "la yuxtaposición de lo histórico y lo contemporáneo, lo político y lo poético, lo factual y lo ficcional, lo discursivo y lo sensual [... y deja un espacio abierto para el uso de la imaginación del lector”. (159, mi traducción) ${ }^{11}$

10 El performance que practica la arqueología es definido de varias maneras en Theatre/Archaeology, pero una de ellas se explica como la coreografía que practican los visitantes en los sitios arqueológicos (restaurados) alrededor de las "trayectorias de movimiento", señas, mapas y explicaciones, que dejan los arqueólogos en estos sitios. (158)

11 Mi descubrimiento de Theatre/Archeology lo debo a la lectura de un artículo de Vicky Unruh que estudia la representación de las ruinas en la obra dramática de la mexicana Sabina Berman. Basada en las ideas

Revista Iberoamericana, Vol. LXXVI, Núms. 232-233 Julio-Diciembre 2010, 695-712
ISSN 0034-9631 (Impreso)


Abandonadas a su suerte y sin más presencia humana que las de Victorio, Salma y Don Fuco, las ruinas del "Pequeño Liceo" contienen la posibilidad interpretativa que destacan Pearson y Shanks. Las ruinas del teatro también presentan la posibilidad de descubrir el "mapa profundo" de narrativas en "diálogo y competencia” y una yuxtaposición entre lo histórico y lo contemporáneo, entre el pasado y el presente que rebasa lo temporal y se extiende a lo generacional. En ellas es posible leer los encuentros y desencuentros entre Estévez y aquellos escritores cubanos que le precedieron: autores como Carpentier y Lezama en quienes la representación de la decadencia urbana funciona como un vehículo de producción de sentidos sobre "lo nacional” y "lo universal".

LA HISTORIA (RE)CREADA

En Los palacios distantes no sólo se favorece la recreación de una historia menos heroica y mitológica que el relato de la Historia Oficial, sino que también se opta por recuperar un fragmento del pasado que el discurso histórico oficial de Estado cubano preferiría dejar en el olvido. Se trata del pasado republicano, del período que comprende las primeras seis décadas del siglo xx: época en que al notar la novela que fue construido y tuvo su apogeo el "Pequeño Liceo" - se recuerda que la princesa rusa manda a construir el teatro en los primeros años de 1900 y que las personalidades cubanas e internacionales que pasan por su escenario pertenecen, sobre todo a las décadas de los cuarenta y cincuenta- se revela en la novela con solemnidad y hasta cierta añoranza. Si se considera lo hasta aquí planteado, se puede decir que es en este período histórico, y no en el que comprende a la Revolución cubana, en el que la novela de Estévez exalta los rasgos de una cultura nacional de alto valor universal. Por las alusiones que hace a la riqueza artística y cultural de la Cuba republicana -período en el que Alvaréz-Tabío Albo también indica que se produce el último "boom" arquitectónico de la ciudad- se puede decir que es en la República donde el texto ubica el pleno apogeo de la modernidad cubana. Esta idea se contrapone al discurso político y cultural de la Revolución.

El historiador cubano Rafael Rojas ha notado cómo en el discurso oficial de la historia nacional, la Revolución de 1959 ocupa el lugar central. Este hecho se percibe en este discurso -un discurso histórico que rige la política educativa, cultural e ideológica del gobierno de Fidel Castro-como el "suceso inaugural de una era gloriosa y definitiva de la historia cubana, en la que, por fin, se realiza el proyecto moderno de una nación

de Pearson y Shanks, Unruh analiza en las ruinas de Berman el reconocimiento de una "otredad” que se resiste a desaparecer y con la que se dialoga. Esta "otredad” son precisamente los espectros del pasado, "los fantasmas” que duermen en las ruinas. En la alegoría que crea entre "fantasma” y “otredad” Unruh abre la posibilidad interpretativa de este concepto, al mismo tiempo que la capacidad cognitiva de las ruinas: los fantasmas devienen "la otredad” que pueden estar no sólo encerradas en las paredes y también en las ideas; la otra cara de la moneda. Véase Unruh.

Revista Iberoamericana, Vol. LXXVI, Núms. 232-233 Julio-Diciembre 2010, 695-712
ISSN 2154-4794 (Electrónico) 
soberana" (Tumbas 385). De acuerdo con esta narrativa oficial que reproducen los aparatos ideológicos del Estado, la historia anterior a la Revolución, dividida en dos épocas fundamentales, la Colonia (1492-1898) y la República (1902-1959), es -en palabras de Rojas- "la prehistoria colonial de la isla". Estos dos períodos son, según Rojas, las dos "páginas en blanco" de la historiografía oficial cubana, una historiografía muy poco dada a los usos de la memoria ("Preguntas").

En su novela Estévez apuesta por rescatar parte de esa historia olvidada, oculta y por lo tanto secreta y lo hace, como es únicamente posible hacerlo cuando el acceso temporal (y espacial) a la misma es casi vedado: a través del uso de la imaginación. Y he aquí, tal vez, la opción del autor de Los palacios por lo republicano, y no por lo colonial -que es el período histórico que Carpentier y Lezama insisten en evocar en su escritura de las ruinas habaneras, como La consagración de la primavera y Paradiso demuestran. La Republica, verdadera incógnita para cualquier escritor cubano nacido en la Revolución, es una etapa que obliga a lo creativo, a lo inventivo, de ahí que su historia sólo sea posible (re)crearla haciendo uso de "lo imaginario". La noción histórica de Estévez se encuentra aquí con la de Lezama, para quien la escritura de la Historia está atravesada siempre por la metáfora o la "imago" y diverge de la de Carpentier, el que la considera una espiral ascendente, dialéctica, progresiva. ${ }^{12}$ De este modo se puede decir que el escritor contemporáneo participa de la misma revelación de "la Cuba secreta" que atribuía María Zambrano a la obra lezamiana, donde el poder imaginativo trasforma "lo local" en universal. ${ }^{13}$

Estévez no sólo hurga en una temporalidad recóndita y olvidada pero además resiste a atribuir al tiempo de la Revolución el carácter "glorioso" y "definitivo" que Rojas menciona. Aparte de los ejemplos de "Papá Robespierre" y "las reliquias profanas de la patria” (algunas de ellas alegorías de trágicos episodios de la historia revolucionaria, como lo son el llanto de los balseros y el recuerdo de artistas cubanos exiliados, y por ello silenciados en la isla, como Celia Cruz), la novela cuestiona los fragmentos de heroicidad que suele invocar la Historia Oficial de la Revolución en su afán de manipulación y dominio del pasado. Un ejemplo significativo al respecto lo constituye en la novela la representación de la muerte de José Martí, prócer patrio sumamente mitificado por el discurso político y cultural nacional -que se produce en la isla y en el exilio- como símbolo indiscutible de "lo cubano." Este hecho invocado con solemnidad y constancia por el discurso oficial de Estado es, más bien, parodiado en la novela, donde se presenta "encapsulado" en una especie de caja de música de cristal con un mecanismo de llave que permite la repetición indefinida del mismo:

12 La concepción de la historia lezamiana es teorizada en los múltiples ensayos que el escritor dedica al tema de "las eras imaginarias". La de Carpentier puede ser vista en casi toda su obra.

13 De ahí el título de las memorias de Estévez, Inventario secreto de La Habana, que son, al mismo tiempo, las memorias de la ciudad.

Revista Iberoamericana, Vol. LXXVI, Núms. 232-233 Julio-Diciembre 2010, 695-712 ISSN 0034-9631 (Impreso) 
El payaso acciona varias veces una llave, y, al compás del Estudio revolucionario de Chopin ejecutado con el tono y los ñoños sonidos de las cajas de música la niebla se disipa. Allí dentro, en la campana de cristal, sobre potro alazán cabalga un hombre con camisa blanca; de pronto algo detiene al jinete, cuya camisa se tiñe de rojo; alza el aterrado alazán las patas delanteras; el jinete cae entre la hierba. Varias veces acciona Don Fuco el mecanismo de la llave de la campana; varias veces puede ver al hombre de la camisa blanca que cabalga y a quien un impacto (¿de bala?) hace caer muerto sobre la hierba. (263)

Toda la escenificación presente en esta “representación”, en especial el accionar del “mecanismo de la llave” vuelve a traer a relucir al elemento performativo. Éste no deja de remitir la invitación de considerar la escritura de la historia como un performance, cuyo material primordial es el uso de lo imaginativo. Desenmascarada la narrativa histórica, queda entonces sólo su materialidad, su consistencia: el lenguaje -el mismo elemento con el que trabaja la literatura. Los límites entre realidad y ficción se borran. El novelista se apropia de lo que, en realidad, le pertenece, "lo imaginario", y decide escribir la Historia, la historia, el relato. Esta escritura se produce así concientemente desde lo inventivo. A través de ella Estévez es capaz de imaginar una etapa pasada a la que le es negada total acceso, que se desvanece -literalmente- y (re)crearla en el presente. El autor de Los palacios conceptualiza así "lo nacional” desde "lo imaginativo", piensa, como Victorio, en un "hipotético Génesis de la ciudad donde se deje escrito: En el principio fue el teatro" (96). ${ }^{14}$

\section{LA RECUPERACIÓN CRÍTICA DEL PASADO}

La recuperación creativa, imaginativa del pasado histórico es posibilitada en Los palacios distantes por la práctica de una memoria subjetiva. A través del relato de sus desencantos, ilusiones, sueños y temores, los personajes de la novela van estructurando una experiencia alternativa a la que se contiene en la historia oficial de la nación. Esta experiencia se construye a través del uso de lo no-lineal y fragmentario (saltos de tiempo, mezcla de voces narrativas, fragmentación del texto en la novela, uso del tema de las ruinas). Esta práctica individual, subjetiva de la memoria, es lo que hace que la escritura de Estévez, en su recreación del pasado, se separe de la política de memorización del Estado. Esto es, del uso de una memoria histórica que apueste por la reconstrucción total y objetiva de lo perdido, de la práctica de lo que Svetlana Boym llama una "nostalgia restauradora”. En su libro The Future of Nostalgia ${ }_{2}$ la crítica rusa define este tipo

${ }_{14}$ Parece necesario hacer notar aquí que el "Pequeño Liceo de La Habana” no existe, ni existió. Es un teatro que Estévez inventa, crea a partir de un modelo real: el teatro "Campoamor" que hoy yace en ruinas en Centro Habana. Este dato me fue provisto por el autor en una entrevista inédita.

$\begin{array}{llllll}\text { Revista Iberoamericana, Vol. LXXVI, Núms. 232-233 Julio-Diciembre 2010, } & \text { 695-712 } \\ \text { ISSN 0034-9631 (Impreso) } & \text { ISSN 2154-4794 (Electrónico) }\end{array}$ 
de nostalgia como aquella que gravita sobre lo colectivo y se manifiesta en la total reconstrucción de monumentos, de emblemas y rituales patrios con el propósito de conquistar y “espacializar el tiempo” (spatialize time). A esta nostalgia Boym opone otra: la "nostalgia reflexiva", un tipo de nostalgia que gravita sobre el individuo y que brota de las piedras de las ruinas, del musgo verdoso del cobre de los monumentos y de los deseos de otro tiempo y lugar. Este tipo de nostalgia, que precisa de la fragmentariedad de la memoria, “temporaliza el espacio” (temporalizes space). Mientras la primera insiste en lo serio y lo ceremonioso, la segunda tiende hacia lo irónico y lo humorístico; y es, en este punto donde, según Boym, precisamente radica el poder crítico de "la nostalgia reflexiva”, la que demuestra que: “el añorar y el pensar críticamente no se oponen como no absuelve la memoria afectiva del uso de la compasión, el juicio y la reflexión crítica” (49-50, mi traducción).

Lo irónico y lo humorístico son dos elementos primordiales que marcan la escritura de Estévez. La opción por “la payasada” que se hace a través del personaje de Don Fuco y, luego, de Victorio no deja de apuntar a este énfasis. En su constante apelación a lo cínico y sarcástico, Los palacios convoca también a otro de los grandes de las letras cubanas: Virgilio Piñera. Más que Carpentier o Lezama, es este escritor el "fantasma” que el autor contemporáneo recupera. El espectro de Piñera - del “escritor maldito” del canon de la literatura cubana, al que Estévez considera su "Maestro"- habita en los trazos fragmentados de la novela. ${ }^{15}$ Esta presencia espectral cobra corporeidad en el epígrafe de la misma: un fragmento de “El gran Baro”, cuento de Piñera que también trata la historia de un payaso. "Nunca he tratado de hacer payasadas, pero ya que usted se empeña, probaré”, reza el epígrafe del que Estévez se apropia “literalmente”, pues retoma la decisión contenida en el mismo y la continúa con la propia escritura de la novela. Los palacios distantes puede considerarse así tanto un homenaje a Piñera como un intento de recuperación de un tipo específico de tradición literaria cubana: aquella que desarrolla la escritura de "lo cubano” dentro del ámbito de "lo negativo"; una tradición que se opone a una visión progresiva y lineal de la Historia, del ser y de la identidad nacional y la resiste con un discurso escéptico, cínico, irónico y humorístico.

Afiliado a esta tradición de la escritura de "lo cubano" - dentro de la cual se puede considerar también a los escritores Guillermo Cabrera Infante, Severo Sarduy y Reinaldo

15 En casi toda su obra Estévez evoca la figura de Virgilio Piñera llamándole "Maestro". Esto es particularmente claro en un pasaje de la primera novela de este escritor Tuyo es el reino (1997): "El Maestro dejó que creciera otro largo y sagrado silencio. Cada vez más íntima, en él se concentraba la luz que bajaba oblicua desde el techo de ramas. Sentí que yo había desaparecido. Al menos así lo creí. Sólo él existía. Cada gesto suyo alcanzaba valor especial. Sacó varios papeles del bolsillo de la descolorida camisa, los desplegó, los llevó a la altura de los ojos. Lo escuché leer [...]: La maldita circunstancia del agua por todas partes me obliga a sentarme en la mesa del café...” (332). La confraternidad que desde su temprana formación como escritor establece Estévez con Piñera, habla también de la marginalidad que el autor de Los palacios asume en relación a la política cultural oficial del Estado cubano.

\begin{tabular}{l} 
Revista Iberoamericana, Vol. LXXVI, Núms. 232-233 Julio-Diciembre 2010, $695-712$ \\
\hline ISSN 0034-9631 (Impreso)
\end{tabular} 
Arenas-, Estévez hace uso en su escritura de una "nostalgia reflexiva" que opone lo ridículo a lo grandilocuente, lo absurdo a lo solemne. Esto es particularmente revelante (y relevante) en uno de los pasajes finales de la novela, cuando Salma mata a su chulo o proxeneta, el Negro Piedad, con un busto de bronce de Martí que hay en las ruinas del teatro. El emblema patrio, cuya solemnidad es otorgada por la "nostalgia restauradora", se presenta en este pasaje como mero objeto, uno que el espíritu burlón de la novela convierte, además, en arma letal. ${ }^{16} \mathrm{Y}$ en este ejercicio, más que desacreditar el valor histórico, político y literario de la figura de José Martí -el que también forma parte de las "reliquias de la patria" que atesoran las ruinas del teatro- Estévez se propone "desenmascarar" los mecanismos del discurso histórico oficial: el "deus ex machina" que utiliza éste para fijar el sentido de "lo nacional”, para encapsular el pasado en el presente, para, como bien resume Boym, "espacializar el tiempo".

Contra la espacialización del tiempo Estévez propone la "temporalización del espacio" propia de la práctica de la "nostalgia reflexiva”; esto es, una relación más dinámica con el espacio de "lo nacional”, una manera de pensar este espacio como un terreno palimpséstico en el que se acumulan un sin fin de capas discursivas, un "profundo mapa" de narrativas en diálogo y competencia, como indican Pearson y Shanks. De ahí la opción en este escritor por la representación de este espacio a través de unas ruinas, de las ruinas de un teatro que apuntan doblemente a una movilidad: aquella sugerida en "el performance", en sus constantes desplazamientos de sentido a través de la máscara y el disfraz, y aquella intrínseca a las propias ruinas, en las que se dan constantes saltos de temporalidad, saltos entre el presente y el pasado. Las ruinas del teatro le ofrecen entonces a Estévez la posibilidad de emitir un contra-discurso de la oficialidad política y cultural que pretende conceptualizar "lo nacional", "lo cubano" desde fórmulas fijas, cerradas, inamovibles. La recuperación del pasado en este escritor se torna así un ejercicio conciente de oposición, de crítica -elemento que Boym también incluye en su conceptualización de la "nostalgia reflexiva"- donde la (re)creación de lo perdido no da lugar a la idealización.

En Los palacios distantes, Estévez no idealiza del todo el pasado republicano, como tampoco idealiza el colonial, ni el revolucionario. Ya se mencionó anteriormente como Don Fuco, el "testigo", el "sobreviviente” de la Historia, expresa su frustración, su desencanto con la "empresa de los hombres" en todas las etapas de ésta" ${ }^{17}$ En la

16 Otro ejemplo del signo ambiguo en que se convierte el Apóstol en esta novela. Al caber en todas las historias, Martí desestabiliza cualquier binarismo fácil.

17 En realidad, Don Fuco - quien dice tener recuerdos del Imperio Romano, de la expansión de los godos, de la Revolución Francesa, de la guerra de las dos Rosas, de Galileo, Mazarino, Goethe, Napoleón, Lenin, Mussolini, Stalin y Machado-, más que con la Historia, se declara rotundamente en contra del Tirano, del Poder: "[T] odos son uno y el mismo, porque aunque hayamos creído que Mussolini, Lenin, Stalin y Machado murieron hace años, es mentira, no murieron, pura suposición, eso cree usted y entiendo yo,

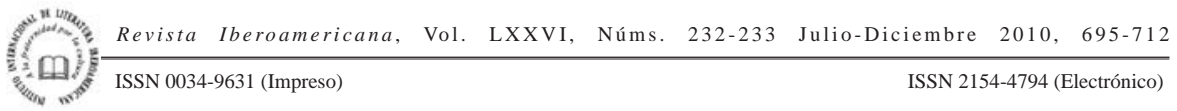


novela, más bien, hay poco sitio para la idealización, pues a pesar de que en ella las ruinas convoquen un "encanto", lo cierto es que el mismo no logra abarcar la realidad: la de los personajes, la del presente del relato. Lo real insiste en burlar los complejos mecanismos de entrada del "Pequeño Liceo" -precisamente, un "deus ex machina" que hace funcionar como elevador una "tumba de Giselle” en el escenario- y lo logra en la presencia de un personaje ya mencionado: el Negro Piedad. En las últimas páginas del texto, el hermoso y a la vez malvado proxeneta disfrazado de policía rompe el encanto provocando la muerte de Don Fuco, su propia muerte y el abandono definitivo de Salma y Victorio de las ruinas del teatro. Los pasajes finales de la novela vuelven así a la expresión de un “desencanto”: los dos personajes arrastrando el cuerpo de Don Fuco por las azoteas de La Habana atemorizados, desfallecidos, desilusionados. El último acto de los mismos parece uno de suicidio, aunque el texto, en su ambigüedad, no lo deja claro:

Luego vieron la ciudad que emergía de las sombras como otra sombra o como una reliquia. ¿Crees que nos necesite?, preguntó ella sin dejar de reír y señalando hacia la lejanía de edificios ruinosos y azoteas maltrechas. Victorio sintió como si se liberara del propio peso, de la maldita ley de gravedad. Salma lo vio erguirse, ridículo y hermoso, con su traje y su repentina alegría. Ahora nos toca a nosotros, respondió él convencido. Y, en efecto, a sus pies dormida aún bajo la lluvia, se hubiera dicho que La Habana era la única ciudad del mundo preparada para acogerlos. También parecía la única superviviente de cuatro largos siglos de fracasos, plagas y derrumbes. (272)

La utopía posible, la que pudiera estar encerrada en una situación de "encanto" desaparece así: no queda lugar para ella en el texto de Estévez, el que termina por declararse profundamente distópico: un quiebre con el idealismo que los mecanismos de escritura del texto ya venían anunciando. ${ }^{18}$ Lo “utópico”, entendido como promesa de un futuro ideal, de un mundo mejor, de futuros "palacios" - precisamente en el sentido que el término tiene dentro del discurso político e ideológico del Estado cubano-, se propone en la novela, como el mismo título indica, “distante”, imposible. De ahí la salida final de Victorio y Salma de las ruinas del teatro: ese espacio en el que pensaban haber descubierto sus palacios (aquel en el que imaginaba la segunda habría de vivir en Hollywood, y el que el Moro aviador prometió, antes de morir, que encontraría en algún lugar el primero). Si hay alguna propuesta utópica en Los palacios distantes ésta

ingenuos como somos, nos negamos a entender que el Tirano es inmortal, el Tirano se reencarna cuando quiere, con el cuerpo y la voz que quiere, el muy mago, el muy perro, el Maligno, se reencarna en cada hombre que ama el poder (103).

18 Difiero así de la opinión crítica de Odette Casamayor Cisneros, quien en un artículo que se dedica al análisis de la representación de las ruinas en la obra de Abilio Estévez, Pedro Juan Gutiérrez y Ena Lucía Portela, considera la novela de Estévez como una propuesta utópica, sin considerar que esa "utopía”, en la insistencia del texto hacia el artificio y la ironía, es concebida desde "lo imaginario".

Revista Iberoamericana, Vol. LXXVI, Núms. 232-233 Julio-Diciembre 2010, 695-712
ISSN 0034-9631 (Impreso) 
sólo sería la que se relega al campo de "lo imaginario" de lo creativo, de la ficción, de la literatura, del arte. ${ }^{19} \mathrm{Al}$ fin y al cabo es el arte, lo literario, la escritura, lo único que permite -como se asegura en la última línea de la novela que hará La Habana"sobrevivir" al desastre.

\section{BiBLIOGRAFÍA}

Álvarez-Tabío Albo, Emma. Invención de La Habana. Barcelona: Casiopea, 2000.

Bauman, Zygmunt. Ética posmoderna. Buenos Aires: Siglo XXI, 2004.

Benjamín, Walter. "Theses on the Philosophy of History". Illuminations. New York: Schocken, 1985.

Boym, Svetlana. The Future of Nostalgia. New York: Basic, 2001.

Casamayor Cisneros, Odette. “¿Cómo vivir las ruinas habaneras de los años noventa?: respuestas disímiles desde la isla en las obras de Abilio Estévez, Pedro Juan Gutiérrez y Ena Lucía Portela”. Caribbean Studies XXXII/2 (July-December 2004): 63-103.

Estévez, Abilio. El horizonte y otros regresos. Barcelona: Tusquets, 1998. Inventario secreto de La Habana. Barcelona: Tusquets, 2005. Los palacios distantes. Barcelona: Tusquets, 2002. Tuyo es el reino. Barcelona: Tusquets, 1997.

Freud, Sigmund. "Mourning and Melancholia". The Freud Reader. Peter Gay, ed. New York: W.W Norton \& Company Inc, 1989. 584-589.

Frietzsche, Peter. Stranded in the Present. Modern Time and the Melancholy of History. Cambridge: Harvard University Press, 2004

Huyssen, Andreas. "Nostalgia for Ruins”. Grey Room 23 (2006): 6-21

Pearson, Mike and Michael Shanks. Theatre/Archaeology. London: Routledge, 2001. Piñera, Virgilio. "El gran Baro”. Cuentos fríos. Buenos Aires: Editorial Losada, 1956. Rojas, Rafael. “Preguntas a una historiografía naciente”. El arte de la espera. Barcelona: Editorial Colibrí, 1998.

Tumbas sin sosiego. Revolución, disidencia y exilio del intelectual cubano. Barcelona: Anagrama, 2006.

Unruh, Vicky. “It's a Sin to Bring Down an Art Deco: Sabina Berman’s Theater among the Ruins”. PMLA 122/1 (January 2007): 135-150.

Webster, John. The Duchess of Malfi. E. Brennan, ed. New York: W.W. Norton \& Co., 1983.

19 Por lo demás, el mejor campo para conceptualizar la utopía, como lo indica el ejemplo de Tomás Moro.

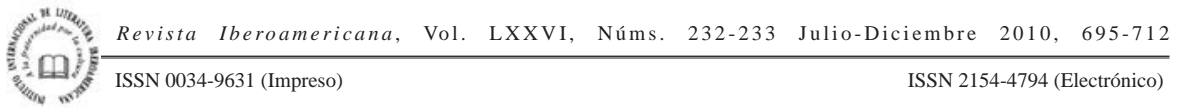

